\title{
Implementing a surgical site infection care bundle: Implications for perioperative practice
}

Follow this and additional works at: https://www.journal.acorn.org.au/jpn

Part of the Health Services Administration Commons, Health Services Research Commons, Perioperative, Operating Room and Surgical Nursing Commons, and the Surgery Commons

(c) (†)

This work is licensed under a Creative Commons Attribution 4.0 License.

\section{Recommended Citation}

Proops, Elaine Michelle (2019) "Implementing a surgical site infection care bundle: Implications for perioperative practice," Journal of Perioperative Nursing: Vol. 32 : Iss. 2 , Article 4.

Available at: https://doi.org/10.26550/2209-1092.1045

https://www.journal.acorn.org.au/jpn/vol32/iss2/4

This Article is brought to you for free and open access by Journal of Perioperative Nursing. It has been accepted for inclusion in Journal of Perioperative Nursing by an authorized editor of Journal of Perioperative Nursing. 


\section{Implementing a surgical site infection care bundle: Implications for perioperative practice}

\section{Introduction}

Surgical care bundles are made up of a group of evidence-based practice interventions which when performed together can have a positive outcome on patient care'. The ACORN Standards for Perioperative Nursing in Australia ${ }^{2}$ outline practices that should be adhered to in Australia; however, practices can be further refined clinically to ensure best practice. Surgical site infection is one of the most preventable causes of hospital-acquired infections in Australia 3 . Research suggests that care bundles implemented by the perioperative team can reduce the incidence of such infections while also offering additional benefits. Surgical site infection intervention bundles can support nurses in their evidence-based practice, contribute to continuing professional development and encourage communication and teamwork. Bundles are simple to implement, can be individualised to each facility and can support culture change using a scale-up approach with long term benefits for the health care organisation.

Care bundles have been implemented into operating theatres internationally and are recognised to reduce surgical site infection through a combination of evidence-based interventions ${ }^{4,5}$. However, the uptake of these bundles in Australian health care is not optimal even though they offer benefits to health care organisations, nurses and patients as well as being able to be implemented on a clinical level as a quality improvement project. Care bundles can be designed and implemented by members of the perioperative team using a collaborative, educational approach that supports evidencebased practices in reducing surgical site infection. Not only do bundles support best nursing practice for better patient outcomes and meet organisation goals, they support the professional development of individual nursing staff members. Through the implementation of bundles, nurses can achieve educational requirements, inspire one another with a shared goal and become individual change agents in the department to support a scaleup practice change approach for long-term benefits.

\section{What is a care bundle?}

The idea of the care bundle was first proposed in 2001 by the Institute for Health care Improvement ${ }^{6}$ to improve teamwork and communication and enhance the consistency and safety of patient care delivery. Bundles specifically targeting areas of harm and cost were divided into three to five achievable evidence-based interventions which exceeded expectations in improving patient outcomes. These structured practices based on existing guidelines aimed to simplify decisions and reduce errors?. Similar projects specifically targeting surgical site infection were later implemented by the Centre for Medicare and Medicaid Services (CMS) in 2003 across the United States of America and later in the United Kingdom by the Department of Health ${ }^{5,8}$. More recently,
Author

Elaine M Proops

MN (Clinical nursing teaching), RN Clinical Nurse Educator (Peri-op),

Campbelltown Private Hospital

Elaine.proops@healthscope.com.au

implementation of care bundles based on Australasian practice was observed to improve standards and consistency in reducing surgical site infection in the Pacific Islands?.

\section{Why is surgical site infection prevention so important?}

The burden of hospital-acquired infection has a considerable effect on health care with nearly 4000 surgical site infections occurring yearly in Australia ${ }^{10}$. Surgical site infection is the most preventable hospitalacquired infection ${ }^{11,12}$. Even though there are many recommendations and standards in place to reduce surgical site infections, they remain one of the most common causes of hospital-acquired infections, occurring in three per cent of surgical procedures ${ }^{3,13}$. Many current interventions are well researched and supported; however, research in health care is constantly being updated. It is imperative for perioperative teams to take responsibility and be accountable for remaining up to date with new evidence and to implement training which promotes an educational team-based approach ${ }^{14}$.

\section{Discussion}

In recent research, care bundles in the perioperative environment were examined in the Netherlands and America in 2017 in three retrospective cohort studies followed by a metaanalysis evaluating the reduction in surgical site infection after care bundle implementation ${ }^{13,15-17}$. Each of the research papers evaluated the incidence of surgical site 
infection reduction in facilities that had implemented a care bundle of similar interventions and found a significant reduction as a result. The meta-analysis found a 40 per cent reduction in surgical site infection and concluded that the implementation of care bundles at a clinical level significantly reduced incidence.

A study conducted in Singapore between 2015 and 2017 looked at bundle interventions and their effect on surgical site infection in hip surgery patients ${ }^{18}$. Although the multifaceted nature of the bundles can make it difficult to pin-point the exact intervention that contributed most to reducing surgical site infections, the collection of interventions over the course of the study showed surgical site infections rates at the reduced rate of 1.8 per cent. However, this retrospective study did not offer a comparison of results, whereas a phased study may have illustrated this. It did demonstrate, however, that effective multidisciplinary involvement with shared responsibilities capitalising on individual nurse strengths and expertise promoted an integrated team-based approach.

Weiser et al. studied the efficacy of a surgical bundle in three phases baseline, implementation and sustainability. A significant decrease in infection was observed during the implementation phase and sustainability of the interventions was demonstrated in the third phase $^{19}$. This was later supported by Hoang et al. who examined bundle implementation in 1351 colorectal surgeries and found not only that infection in deep and superficial wounds was reduced but also that compliance with evidencebased practice increased and was continued ${ }^{20}$. The study illustrated that the small changes implemented led to significant changes in practice over time.

\section{Professional development opportunity for nurses}

Registration with the Australian Health Practitioner Regulator Agency (AHPRA) as either an enrolled or a registered nurse requires demonstrating that 20 hours of continuing professional development have been completed over the course of 12 months $^{21}$. This requirement ensures that we, as perioperative nurses, stay up to date, maintain our knowledge and remain inspired to provide better care outcomes. However, many nurses express that it is difficult to maintain this while juggling full-time work, family commitments and additional responsibilities. Nurse involvement in the development and design of the care bundle process from the beginning and driving the project while maintaining responsibility and accountability can inspire nurses to contribute by improving areas in which they are most interested. In addition, opportunities for quality improvement activities among clinical staff can enhance team morale, support evidencebased practice, initiate team communication and inspire new ideas among staff ${ }^{16}$.

\section{Aren't nurses currently practising through an evidence-based approach?}

\section{Australian perioperative nursing} practice is currently governed by Standards for Perioperative Nursing in Australia which includes standards and guidelines that are closely aligned with similar international standards ${ }^{22}$. They are designed to provide detailed specifications of nursing practices that have been rigorously assessed for credibility, reliability and consistency ${ }^{23}$. Although all registered nurses endeavour to deliver safe patient care according to the most up-to-date evidence available for practice ${ }^{23}$, research suggests that nurses often practise in ways other than those which follow the rules and standards ${ }^{22}$. While the Australian Commission on Safety and Quality in Health Care encourages an evidence-based approach, perioperative nurses feel that lack of time, support and education commonly prevents the implementation of evidencebased practice ${ }^{24}$. Improved practices are constantly emerging through research; however, transition and uptake into practice is delayed while nurses lack tools and support. Becoming an evidence-informed practitioner can be overwhelming, especially in a culture that does not foster change, and can be a complex process to put into practice $^{24}$. Bingham et al. ${ }^{22}$ found that perioperative nurses find it challenging to meet the needs of patients as well as the demands of doctors, the team and the health care organisation and this may lead to deviations from recommended practices. Surgical bundle development can assist the clinical nurse to integrate evidence into practice while supporting nurses to speak up and scrutinise current practice.

How do I implement a care bundle in the perioperative environment?

Surgical site infection bundles can be implemented relatively rapidly in health care facilities, with the Standards for Perioperative Nursing in Australia and other hospital policy resources ${ }^{25}$ providing a basis for recommended practice. It is not a case of there being a particular bundle which it is recommended to implement; instead, bundles can be tailored to health care facilities based on the facility's needs and specialities. Care bundle interventions enhance how the 
existing policies and procedures are achieved rather than replacing or changing hospital policies and other documentation already in place.

Perioperative nurse educators as well as clinical nurses can reflect on current departmental practices and identify opportunities for improvement which reflect their own expertise and interests ${ }^{3,26}$. They would then research areas of individual interest and, based on the literature and recommendations available, develop interventions and share them with colleagues, peers and key players $^{27,28}$.

Implementing evidence-based practice can be challenging, while a top-down approach to change stemming from managers and administrators may not foster culture change easily ${ }^{29}$. A bottomup approach to fostering cultural change in health care organisations in which each member is supported as a change agent to implement improvements in their own practice can yield permanent positive change more effectively ${ }^{30}$.

\section{Examples of evidence-based bundle interventions}

\section{Scrub-scout nurse role}

1. Removal of hair from the operating site should be avoided unless completely necessary ${ }^{31}$. If the surgeon feels that hair at the surgical site should be removed it is recommended that clipping should be done as close to the commencement of the procedure; however, it should be done outside the operating room ${ }^{32}$.

2. Excessive theatre traffic and opening of the operating door increases air-borne bacteria, increasing the risk of surgical site infection. A maximum number of door openings should be agreed upon for each speciality of surgery ${ }^{33}$. Measures should be taken to ensure that door openings are kept within this number.

3. Incise adhesive drapes, impregnated or not, should not be used for the purpose of preventing surgical site infection ${ }^{31}$ However, they do offer additional benefits which may be considered important in practice.

4. Changing of gloves prior to wound closure has been demonstrated as having a significant reduction in surgical site infection incidence ${ }^{13}$.

\section{Anaesthetic nurse}

1. Active warming via a warming device, as opposed to passive warming, should be used for patients undergoing a surgical procedure $^{33}$.

2. Blood glucose levels for both diabetic and non-diabetic adult patients undergoing a surgical procedure should be closely monitored by the anaesthetic team with the aim of reducing surgical site infection ${ }^{31,34}$.

3. Education and monitoring of hand hygiene for anaesthetic staff has been identified as an area of improvement in the operating room. Strategic placement of alcohol-based hand rub and non-sterile gloves may support compliance $^{35}$.

\section{Conclusion}

Surgical care bundles have been implemented in health care facilities internationally for nearly two decades and offer many benefits to health care organisations, clinical staff and hospital patients. The risk of infection is reduced when all interventions that make up care bundles are performed every time and for every patient. Although
Australian health care facilities abide by guidelines and recommendations, new and improved practices are constantly being researched and nurses need the support, tools and confidence to integrate these into their practice. Surgical care bundles can facilitate improved practices; support continuing professional development, communication and teamwork; improve morale; and inspire nurses to share a vision of an improved health care service for patients.

Care bundles empower nurses to make changes for the better through a scale-up approach that supports cultural change with long-term benefits for all involved. These small interventions aligned with hospital policies and the ACORN standards can make a significant difference to the quality of life for patients through reducing their risk of developing a surgical site infection with an extended hospital stay and through lowering morbidity and mortality. Surgical care bundles are simple to implement and can make an enormous difference to rates of hospital-acquired infection in health care facilities throughout Australia.

\section{References}

1. Lowman $\mathbf{W}$. Interpreting the evidence base for 'Bundles' in prevention of surgical site infections [Internet]. Parktown, S.A: Wits School of Pathology; 2016 [cited 2019 January 2]. Available from: pdfs.semanticscholar.org/bbbe/ fca4118ea1d8f5d5de1da1042b75871629bb.pdf.

2. Australian College of Perioperative Nurses Ltd (ACORN). Standards for Perioperative Nursing in Australia $15^{\text {th }}$ ed. Adelaide, South Australia: ACORN, 2018.

3. Australian Commission on Safety and Quality in Health care (ACSQH). Approaches to surgical site infection surveillance for acute care setting in Australia [Internet]. Sydney: ACSQH; 2017 [cited 2019 January 19]. Available from: www.safetyandquality gov.au/wp-content/uploads/2017/07/ Approaches-to-Surgical-Site-InfectionSurveillance.pdf. 
4. Tanner J, Padley W, Assadian O, Leaper D, Kiernan M, Edmiston C et al. Do surgical care bundles reduce the risk of surgical site infections in patients undergoing colorectal surgery? A systematic review and cohort meta-analysis of 8,515 patients. Surgery 2015;158(1):66-77. doi:10.1016/j. surg.2015.03.009.

5. Anderson DJ, Podgorny K, Berríos-Torres SI, Bratzler DW, Dellinger $P$ et al. Strategies to prevent surgical site infections in acute care hospitals: Infect Control Hosp Epidemiol 2014;(35):605-627. doi:10.1086/676022.

6. Resar R, Griffin FA, Haraden C, Nolan TW. Using care bundles to improve health care quality, IHI innovation series white paper [Internet]. Cambridge, MA: Institute for Healthcare Improvement; 2012 (cited 2019 January 9). Available from: www.ihi. org/resources/Pages/IHIWhitePapers/ UsingCareBundles.aspx.

7. Camporota L, Brett S. Care bundles: Implementing evidence or common sense? Crit Care 2011;15(3):159. Available from: www.ccforum.biomedcentral.com/ articles/10.1186/cc10232

8. Department of Health (UK). High impact intervention: Care bundle to prevent surgical site infection [Internet]. London: Dpartment of Health; 2011 [cited 2019 March 12]. Available from: webarchive. nationalarchives.gov.uk/20120118171639/ http:/ / hcai.dh.gov.uk/files/2011/03/201103-14-HII-Prevent-Surgical-Siteinfection-FINAL.pdf.

9. Davies M, Sutherland-Fraser S, Taoi M, Williams C. Developing standards in Pacific Island countries: The Pacific perioperative practice bundle (part 1). ACORN J 2016;29(2):42-47.

10. Mitchell BG, Shaban RZ, MacBeth D, Wood C, Russo PL. The burden of healthcareassociated infection in Australian hospitals: A systematic review of the literature. Infection, Disease and Health 2017;(22)117128. Available from: www.idhjournal.com.au/ article/S2468-0451(17)30043-3/pdf.

11. Harbarth S, Sax H, Gastmeier P. The preventable proportion of nosocomial infections: An overview of published reports. J Hosp Infect 2003:54(4):258-266. Available from: www.sciencedirect.com/science/ article/pii/S0195670103001506.

12. Centers for Disease Control and Prevention (CDC). Surgical Site Infection. Atlanta: CDC; 2012 (cited 2019 January 9). Available from: www.cdc.gov/HAl/ssi/ssi.html.

13. Zywot A, Lau CSM, Fletcher S, Paul S. Bundles prevent surgical site infections after colorectal surgery: Meta-analysis and systematic review. J Gastrointest Surg 2017;21(11):1915-1930.

14. Spruce L. Back to basics: Preventing surgical site infections. ACORN J 2016;29(3):13-18.
15. Koek MBG, Hopmans TEM, Soetens LC, Wille JC, Geering SE, Vos MC et al. Adhering to a national surgical care bundle reduced the risk of surgical site infections. Plos One 2017;12(9):e0184200.

16. Losh JM, Gough A, Rutherford R, Romero R, Diaz G, Schweitzer J. Surgical site infection reduction bundle: Implementation and challenges at Ventura County Medical Center. Am Surg 2017;83(10):1147-1151.

17. Bert F, Giacomelli S, Amprino V, Pieve $G$, Ceresetti D, Testa M et al. The bundle approach to reduce the surgical site infection rate. J Eval Clin Pract 2017;23(30):642-647.

18. Mok WQ, Ullal MJ, Su S, Yiap PL, Yu LH, Lim SMM et al. An integrative care bundle to prevent surgical site infections among surgical hip patients: A retrospective cohort study. Am J Infection Control 2018:S01966553(18)31025-3. doi: 10.1016/j.ajic.2018.10.011.

19. Weiser M.R, Gonan S, Usiak T, Pottinger P, Samedy D, Patel S et al. Effectiveness of a multidisciplinary patient care bundle for reducing surgical site infection. Br J Surg 2018;105(12):1680-1687.

20. Hoang SC, Klipfel AA, Roth LA, Vrees M, Schechter S, Shah N. Colon and rectal surgery surgical site infection reduction bundle: To improve is to change. Am J Surg 2019;217(1):40-45.

21. Bryce J, Foley E, Reeves. CPD - whats the point? Aust Nurs Midwifery J 2017;25(4):23. Available from: search.proquest.com/openvi ew/20444c82c9521baf188b66a2b56b4b46/1? pq-origsite $=$ gscholar $\& c b l=33490$.

22. Bingham S, Walsh K, Ford K. Reshaping perioperative nursing practice to get the job done: A constructivist grounded theory study. Journal of Perioperative Nursing 2018;31(1):19-29.

23. Osborne S. Making evidence-based perioperative practices stick: An introduction to an implementation science approach. Journal of Perioperative Nursing 2017;30(4):53-55.

24. Duff J, Butler M, Davies M, Williams R, Carlile J. Perioperative nurses' knowledge, practice, attitude and perceived barriers to evidence use: A multisite, cross-sectional survey. ACORN J 2014;27(4):28-35

25. Krantz T, Dunivan G. Putting surgical site infection bundles into practise: Rates of post-hysterectomy infection have been shown to lower in hospital that have adopted evidence-based guidelines for preventing post-surgical infections [Internet]. New York: Contemporary Ob/Gyn; 2018 [cited 2019 January 2]. Available from: www.contemporaryobgyn.net/gynecologicsurgery/putting-surgical-site-infectionbundles-practice.
26. Duff J, Walker K, Edward K. Collaborative development of a perioperative thermal care bundle using the guideline implement ability appraisal. J Perianesth Nurs 2016:33(1)13-22. doi: 10.1016/j. jopan.2016.05.007.

27. Duff J, Walker K, Edward K, Williams $\mathrm{R}$, Sutherland-Fraser S. Incidence of perioperative inadvertent hypothermia and compliance with evidence-based recommendations at four Australian hospitals: A retrospective chart audit. ACORN J 2014;27(3):16.

28. Duff J, Walker K, Edward K. L, Ralph N, Giandinoto JA, Alexander K et al. Effect of a thermal care bundle on the prevention, detection and treatment of perioperative inadvertent hypothermia. J Clin Nurs 2018;27(5-6):1239-1249.

29. Mick J. Call to action: How to implement evidence-based nursing practice. Nursing 2017;47(4)36-43.

30. World Health Organization (WHO). Guide to fostering change to scale up effective health services [Internet]. Geneva: WHO; 2013 [cited 2019 March 11]. Available from: apps.who.int/iris/bitstream/ handle/10665/96611/9789241506588_eng. pdf;jsessionid=C44381CB42A8515CD2 757109198E20BE?sequence=1.

31. World Health Organization (WHO). Globa guidelines for the prevention of surgical site infection [Internet]. Geneva: WHO; 2016 [cited 2019 January 21]. Available from: www. who.int/gpsc/appendix13.pdf.

32. Bashaw M, Keister K. Perioperative strategies for surgical site infection prevention. AORN J 2019;109(1):68-78.

33. Smith EB, Raphael DJ, Maltenfort MG, Dolan K, Younkins EA. The effect of laminar air flow and door openings on operating room contamination. J Arthroplasty 2013;28(9):1482-1485.

34. Gachabayov M, Senagore AJ, Abbas SK, Yelika SB, You K, Bergamaschi R. Perioperative hyperglycemia: An unmet need within a surgical site infection bundle. Tech Coloproctol 2018;22(3)201-207.

35. Munoz-Price $S$, Bowdle A, Johnston L, Bearman G, Camins B, Dellinger $P$ et al. Infection prevention in the operating room anesthesia work area. Infect Control Hosp Epidemiol 2019;(40)1-17. doi:10.1017/ ice.2018.303. 